\title{
ESCULTURA CASTELLANA DEL RENACIMIENTO Y BARROCO EN EL MUSEU NACIONAL D’ART DE CATALUNYA
}

En el Museu Nacional d'Art de Catalunya (MNAC) existe una colección de escultura de la época del Renacimiento y Barroco formada por más de 500 obras, de las cuales pocas están a la vista del público. Por lo tanto, no es de extrañar que se trate de una colección bastante desconocida, también entre los investigadores en historia del arte. A falta de un catálogo razonado de las obras adscritas a nuestra área, el objetivo del presente artículo es estudiar una selección de esculturas de los fondos del MNAC, obras de gran interés artístico, la mayoría de las cuales son inéditas. En total son nueve: atribuible a la importación flamenca, al círculo de Felipe Bigarny, a un colaborador de Diego de Siloé, a Jerónimo Hernández, al taller de Juan de Anchieta, a un seguidor de Juan de Juni, a Manuel Pereira, a un discípulo de Gregorio Fernández y a un seguidor de Luis Salvador Carmona.

Palabras clave: Escultura; Renacimiento; Barroco; Museu Nacional d'Art de Catalunya (MNAC).

In the Museu Nacional d'Art de Catalunya (MNAC) in Barcelona there is a collection of some 500 works of sculpture dating from the Renaissance and Baroque periods, few of them on public display. Thus this collection is not well known, even among art historians. Given the lack of a complete catalogue of these works, the purpose of this 
article is to present a selection of sculptures in the MNAC, all of great artistic interest, the majority of them unpublished. They are nine in all: attributed to Flemish importation, to the circle of Felipe Bigarny, to a collaborator of Diego de Siloé, to Jerónimo Hernández, to the studio of Juan de Anchieta, to a follower of Juan de Juni, to Manuel Pereira, to a disciple of Gregorio Fernández and to a follower of Luis Salvador Carmona.

Key words: Sculpture; Renaissance; Baroque; Museu Nacional d'Art de Catalunya (MNAC).

La apertura al público de los ámbitos correspondientes a la colección de Arte del Renacimiento y el Barroco del Museu Nacional d'Art de Catalunya (MNAC) tuvo lugar en diciembre de $2004^{1}$. En este museo existe una colección de escultura de los siglos XVI, XVII y XVIII formada por más de 500 obras, de las cuales sólo 43 piezas (de 31 conjuntos) están a la vista del espectador (a diciembre de 2008). Se trata de una colección bastante desconocida, también entre los investigadores en historia del arte, debido al cierre de los ámbitos del museo dedicados al arte renacentista y barroco durante casi 28 años, entre inicios de 1977 y finales de 2004, sólo atenuado por una breve apertura de pocos meses entre 1985 y $1986^{2}$. El objetivo del presente artículo es estudiar una selección de esculturas del fondo del MNAC, obras en relación con el arte de Castilla, la mayoría de las cuales son inéditas.

\section{Renacimiento: importación "flamenca”, círculo Bigarny y colaborador de Siloé}

Con el número de inventario 5224, y adquirido a la colección Plandiura en 1932, hallamos un relicario en madera de roble policromado y dorado que mide $44 \times 32 \times 18 \mathrm{~cm}$. (fig. 1 ). El relicario representa el busto de una santa indeterminada, una joven dama con cabellos largos que le caen sobre el hombro; los restos se alojaban en el interior del cráneo de la escultura. Va vestida a la moda flamenca de inicios del siglo XVI, lleva una diadema de pedrería que alude a su condición noble, una túnica de escote cuadrado que deja ver una blusa, y un collar que cuelga de su cuello con una cadena; finalmente un manto anudado sobre el hombro izquierdo. Es un ejemplar exquisito, quizás sea una de las once mil vírgenes que acompañaron a santa Úrsula, pues, este idéntico modelo fue usado en otros bustos relicarios similares, como los bustos relicarios de Úbeda conservados en el The Cloisters de Nueva York, uno andaluz que encontramos en el Staatliche Museum de Berlín, un par que hay en el Museo de los Caminos de Astorga, y otro par que se conserva en el Museo de Arte Sacro de Vitoria-Gasteiz ${ }^{3}$. Todas estas obras han sido puestas en relación con los talleres escultóricos de Brabante, sobre todo los activos en la ciudad de Bruselas entre 1520 y 1530. En definitiva, otro ejemplo del comercio artístico que hubo entre los Países Bajos meridionales y Castilla durante el siglo XV y las primeras décadas del siglo XVI ${ }^{4}$.

\footnotetext{
${ }^{1}$ Este artículo no habría sido posible sin la ayuda, la comprensión y los sabios consejos de M. Margarita Cuyás, Margarita M. Estella y Carmen Morte.

2 Este vacío fue mitigado por las exposiciones temporales de parte de los fondos, aunque las exposiciones acostumbran a marginar los corpus escultóricos. De esta regla, casi general, hubo un par de excepciones: L'època dels genis. Renaixement. Barroc, realizada en 1987 en Girona y en 1989 en Barcelona; o Itineraris de l'art català. Les col-leccions del MNAC: Renaixement i Barroc, hecha entre 2003 y 2004 en Sitges, Sabadell, Igualada, Manresa, Mataró, Santa Coloma de Gramenet y Gavà.

${ }^{3}$ Hernández Redondo, José Ignacio, "Bustos relicarios de dos de las once mil vírgenes", Encrucijadas (Catálogo de la exposición "Las Edades del Hombre". Astorga, 4 de mayo-5 de noviembre de 2000), Salamanca, 2000, pp. 352-354; López Redondo, Amparo, "Anónimo, Escuela flamenca, Taller de Brabante. Bustos-relicario santas Vírgenes", Erasmo en España. La recepción del humanismo en el primer Renacimiento español (Catálogo de la exposición. Salamanca, Escuelas Menores de la Universidad, 26 de septiembre de 2002-6 de enero de 2003), Madrid, 2002, pp. 322-323.

${ }^{4}$ Véase: Martínez de Aguirre, Javier, "Notas sobre la importación de obras escultóricas en la Castilla bajomedieval”, J. YARZA-A. C. IbÁÑEz (dirs.), Actas del Congreso Internacional sobre Gil Siloé y la escultura de su época
} 


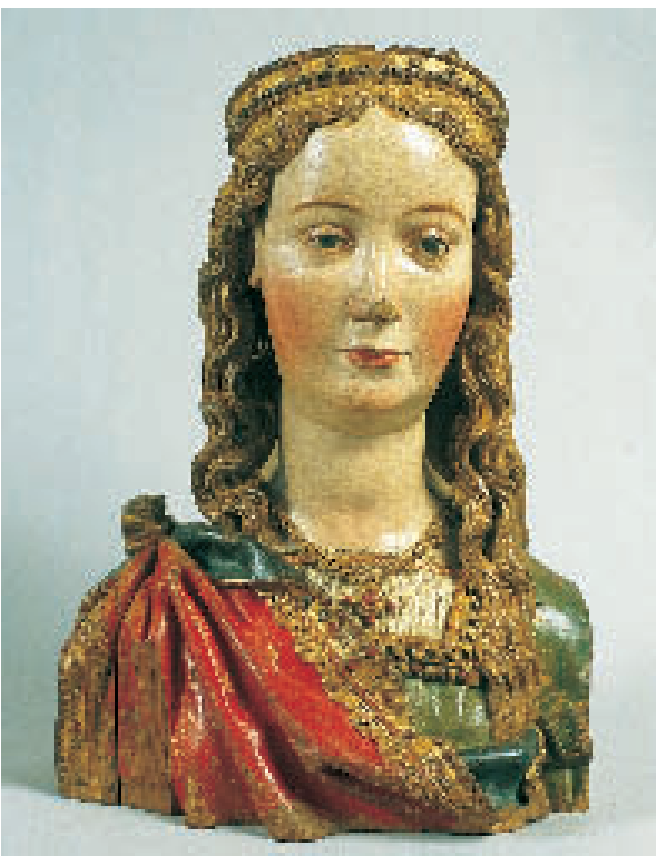

Fig. 1. Taller de Brabante, busto relicario de una santa virgen, 1520-1530 C).

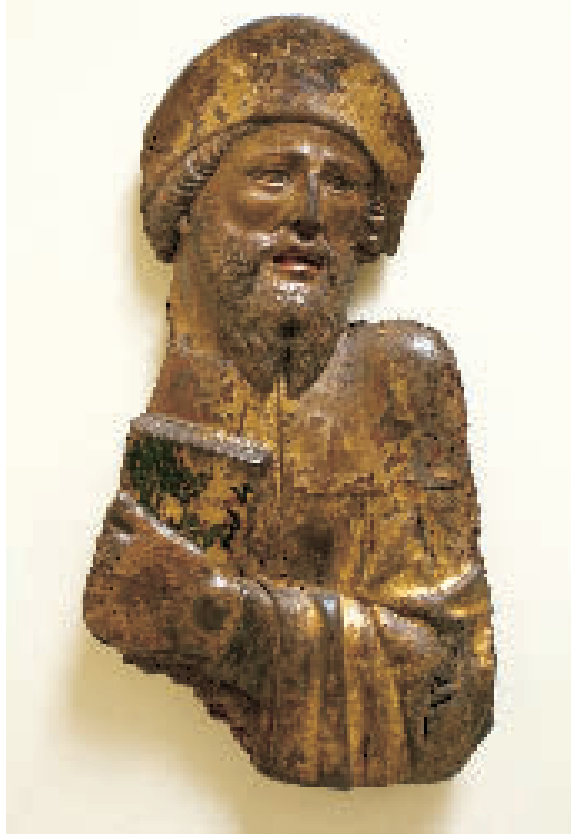

Fig. 2. Maestro del altar del Sagrario, Santiago Apóstol, 1515-1535 (C).

Con el número de inventario 4357, también adquirido en 1932 a la colección Plandiura, existe un relieve en madera policromada y dorada que mide $52 \times 28 \times 5 \mathrm{~cm}$. Se trata de un fragmento que podría haber formado parte de una sillería de coro, como respaldo, y representa el busto del apóstol Santiago el Mayor (fig. 2). La figura aparece barbada, con la boca entreabierta, un sombrero con conchas, y en su mano izquierda lleva un libro. A pesar de la mutilación y la precariedad de conservación, se trata de una obra de gran calidad. La combinación entre el estilo del relieve y el tipo de peinado, responde a los parámetros cronológicos entre 1515 y 1535 y al entorno artístico de Felipe Bigarny (Marmagne?, hacia 1470-Toledo, 1542). En concreto, nos encontramos ante un estilo próximo a las obras que Bigarny realiza en Cervera de Pisuerga entre $1512-1514$ y a las obras de la capilla real de Granada entre 1520-1522, por la ejecución de la barba partida de por medio (o barba bífida) y la manera de hacer los labios carnosos ${ }^{5}$. Dentro de la órbita de los discípulos y seguidores de Bigarny, tiene mucho parecido con figuras del retablo de Santiago en la iglesia parroquial de Sasamón (Burgos), datados alrededor de 15306. O también con el retablo de la capilla de san Gregorio, en la catedral de Palencia, fechado hacia 1533 y vinculado al círculo de Bigarny, a cuyo autor Weise bautizó con el nombre de "Maestro del

(Burgos, 13-16 de octubre de 1999), Burgos, 2001, pp. 367-380; GómEz BÁrcenA, María Jesús, "Arte y devoción en las obras importadas. Los retablos 'flamencos' esculpidos tardogóticos: estado de la cuestión”, Anales de Historia del Arte, 14, 2004, pp. 33-71.

5 Río DE La Hoz, Isabel del, El escultor Felipe Bigarny (h. 1470-1542), Salamanca, 2001, pp. 115-116 y 162-179.

6 Véase: Payo Herranz, René Jesús, "Martirio de Santiago" y "Colocación del cuerpo de Santiago en la barca", Yo camino (Catálogo de la exposición "Las Edades del Hombre". Ponferrada, mayo-diciembre de 2007), León, 2007, pp. 111-114. 
altar del Sagrario" (debido a otra obra palentina); nótese el personaje barbado en el relieve del martirio de santa Catalina ${ }^{7}$. Por lo tanto, sería un colaborador de Bigarny afincado en Palencia, un bigarnista bajo la influencia siloesca, que notamos en el soberbio escorzo del rostro. Según Del Río, la técnica y la tipología de retrato de Juan de Valmaseda (Balmaseda?, hacia 1487-Palencia, 1548) son los mismos que Bigarny, y pone un ejemplo con el retablo de san Bartolomé en la iglesia de San Esteban de Burgos (1519-1520), el cual "pasaría por ser de Bigarny si no fuese que contamos con el documento del contrato hecho a Valmaseda" ¿. ¿Un Valmaseda diferente al escultor expresivo que conocemos? Para más dudas, compárese la obra del MNAC a obras atribuidas a Valmaseda: el Ecce Homo de la parroquial de Villamediana (Palencia), fechada entre 1530-15359; o el Santiago peregrino que encontramos en la parroquial de Villalcázar de Sirga (Palencia), fechada hacia el $1530^{10}$.

En 1961 se publicó el Catálogo Monumental de Medina del Campo, en el cual registraba que en la iglesia de San Miguel se encontraba la Virgen de las Candelas ${ }^{11}$. Hoy hallamos esta obra en el MNAC con el número de inventario 131050, legada por José Antonio Bertrand Mata en 1970, e ingresada en el museo en $1981^{12}$ (fig. 3). Se trata de una Virgen que sostiene al Niño con las dos manos, que se apoya sobre una base circular, una obra en madera policromada y dorada, que mide $110 \times 39 \times 43 \mathrm{~cm}$. Ella viste túnica azul noche con orla decorada de motivos vegetales y estola cruzada sobre el pecho, velo dorado que deja al descubierto parte de su cabello ondulado, manto terciado sobre el hombro izquierdo que se reúne en su antebrazo derecho, con orla de características iguales a las de la túnica. El Niño, sentado de lado, con las piernas descubiertas e inclinadas hacia el centro, tiene la mano izquierda apoyada sobre el pecho de la Madre, y lleva túnica adornada como la de su madre. La escultura se debe fechar a inicios del segundo cuarto del siglo XVI, entre 1530-1540, bajo la influencia, de raíz rafaelesca, que ejerció Diego de Siloé. La obra es excelente, y sólo podía ser realizada por el propio Siloé o un miembro de su taller próximo al maestro. Aunque se hallan diferentes elementos para atribuirla directamente a Siloé, existen dos inconvenientes de peso: el excesivo movimiento que transmiten los pliegues enroscados, y que la fecha ante quem sería 1528, momento de su traslado a Granada. El taller castellano de Siloé no ha sido estudiado a fondo, sólo se documentan ayudantes puntuales, y no fieles colaboradores ${ }^{13}$. Por lo tanto, sería un escultor activo a partir de 1530, formado con Diego de Siloé o Alonso Berruguete, pero con contactos con los talleres burgaleses arraigados en la tradición de Felipe Bigarny ${ }^{14}$. La postura del Niño, en posición sesgada y en torsión, tiene muchos

7 WeISE, Georg, Spanische plastik aus sieben Jahrhunderten, Reutlingen, 1925-1932, vol. II, pp. 189 ss.; PORTELA Sandoval, Francisco, La escultura del Renacimiento en Palencia, Palencia, 1977, pp. 82-106.

${ }^{8}$ Río DE LA Hoz, I. del, El escultor Felipe Bigarny... (op. cit.), pp. 122-123.

9 Hernández Redondo, José Ignacio, “36. Juan de Valmaseda. Ecce Homo”, Memorias y esplendores (Catálogo de la exposición "Las Edades del Hombre", Palencia, 12 de abril-31 de octubre de 1999), Palencia, 1999, pp. 172-173.

${ }^{10}$ Parrado del Olmo, Jesús María, "104. Santiago peregrino. Juan de Valmaseda”, Yo camino... (op. cit.), pp. 218-219.

${ }^{11}$ García Chico, Esteban, Catálogo monumental de la provincia de Valladolid. Medina del Campo, Valladolid, 1961, vol. III, p. 117 y fig. XCI.

12 Col-leccions Bertrand als Museus de Barcelona, Barcelona, 1985, p. 32.

13 Por ejemplo, los entalladores Juan González y Juan García, documentados en el sepulcro de Antonio de Rojas para la iglesia del monasterio de Santa María de Gracia, en Villasilos (Burgos). Véase: Castro García, Lázaro de, "Diego de Siloé y el sepulcro del obispo burgalés de don Antonio de Rojas", Boletín de la Institución Fernán González, 183, 1974, pp. 319-321; Mediavilla, Aniano, "Juan González y Juan García: entalladores de Santoyo", Publicaciones de la Institución Tello Téllez de Meneses, 43, 1979, pp. 103-113.

14 Véase: Parrado del Olmo, Jesús María, Los escultores seguidores de Berruguete en Palencia, Valladolid, 1981; Parrado del Olmo, Jesús María, "Precisiones sobre escultura palentina del siglo XVI. Nuevas atribuciones al taller bigarnista-siloesco", Actas del I Congreso de Historia de Palencia, Palencia, 1987, vol. I, pp. 147-159. 
rasgos en común con la que podemos observar en una obra conservada en la villa de Santiago de la Puebla (Salamanca), obra documentada de Diego de Siloé hacia $1523^{15}$. El rostro de la Virgen del MNAC también se puede relacionar con la Virgen que Siloé realiza para la Presentación al templo en el retablo de la capilla del Condestable (1522-1526), catedral de Burgos. Las manos recuerdan las de la Virgen de la Expectación, conservada en el Museo de Santa Cruz, Toledo, procedente de la iglesia de San Francisco en Carrión de los Condes (Palencia); considerada por Speranza, entre otros, como de taller siloesco, aunque Weise la relacionó con Juan de Valmase$\mathrm{da}^{16}$. La obra más próxima a la escultura del MNAC es la Virgen con el Niño que se conserva en el santuario de Santa Casilda, en Salinillas de Bureba (Burgos); obra que Gómez-Moreno califica de siloesca, pero cualitativamente por debajo del maestro burgalés ${ }^{17}$.

\section{Manierismo y romanismo: Jerónimo Hernández, taller de Anchieta y seguidor de Juni}

En 1901 Gómez-Moreno realizó un inventario de la provincia de Ávila, en el cual registraba que en el monasterio de Santa María del Real de Arévalo había una estatua de la Virgen con el Niño bendiciendo, junto con un san Miguel, "muy elegantes y de mérito. Quizá, obras italianas; siglo XVI"; pero, cuando tuvo lugar la publicación del inventario en 1983, las obras estaban "desaparecidas ambas" ${ }^{18}$. Hoy hallamos esta obra en el MNAC con el número de inventario 131058, legada por José Antonio Bertrand Mata en 1970, e ingresada en el museo en $1981^{19}$ (fig. 4). Una imagen en madera policromada y dorada que mide $158 \times 49 \times 50,5 \mathrm{~cm}$, una Virgen que se alza sobre unas nubes, de las cuales salen las dos puntas de la luna y cuatro cabezas de querubín. Viste túnica dorada, faja azul con decoración llameada, manto terciado sobre el hombro derecho de color azul, decoración vegetal y forro rojo. La figura se cubre con un velo blanco sujeto por una diadema, la cual deja al descubierto parte del pelo ondulado. Sostiene al Niño con las dos manos, mientras éste está sentado de lado sobre la mano izquierda de su Madre, viste pañales, y bendice con su mano derecha. Según Estella, esta obra tiene relación con las imágenes marianas de Juan Bautista Vázquez el Viejo, pero su falta de movimiento la hacen decantar por el estilo de su discípulo Jerónimo Hernández de Estrada (Ávila, hacia 1540-Sevilla, 1586) ${ }^{20}$. La llegada de Vázquez a Sevilla no se documenta hasta 1561, y la actividad andaluza de Hernández no es interrumpida hasta después de 1565 , unas fechas que no tienen que fijar un límite de realización escultórica, pues el estilo de trabajar los cabellos nos remite a una cronología entre 1565 y 1580. El rostro de la Virgen del MNAC recuerda a obras de Hernández, como la Virgen de la Paz de la iglesia parroquial de Santa Cruz en Sevilla, fechada entre 1577-1578, o la Virgen de la Granada

\footnotetext{
15 Una torsión del Niño que se ha puesto en relación con la Virgen con el Niño de Andrea Sansovino en la iglesia de Sant'Agostino de Roma (1512), y, quizás inspirado, en la Virgen Bridgewater de Rafael en la National Gallery de Edimburgo (1507). Véase: SperanZA, Fabio, "Diego de Siloe, Felipe Bigarny e una cappella rinascimentale in provincia di Salamanca", Studi di Storia dell'Arte, 11, 2000, pp. 73-96.

16 Speranza, Fabio, "Ha de ser de obra del romano". Diego de Siloe tra Napoli e Burgos, Nápoles, 2000 (tesis doctoral inédita, Università degli Studi "Federico II", dirigida per la Dra. Fiorella Sricchia Santoro); WeISE, G., Spanische plastik... (op. cit.), vol. III, p. 220.

17 Gómez-Moreno, Manuel, Las águilas del renacimiento español: Bartolomé Ordóñez, Diego Siloé, Pedro Machuca, Alonso Berruguete 1517-1558, 1941 (edición consultada: Madrid, 1983), p. 46.

18 Gómez-Moreno, Manuel, Catálogo monumental de la provincia de Ávila, Ávila, 1983, vol. I, 246; vol. II, foto 592.

19 Col-leccions Bertrand als Museus de Barcelona, Barcelona, 1985, p. 36.

20 Estella Marcos, Margarita, Juan Bautista Vázquez el Viejo en Castilla y América. Nicolás de Vergara, su colaborador, Madrid, 1990.
} 


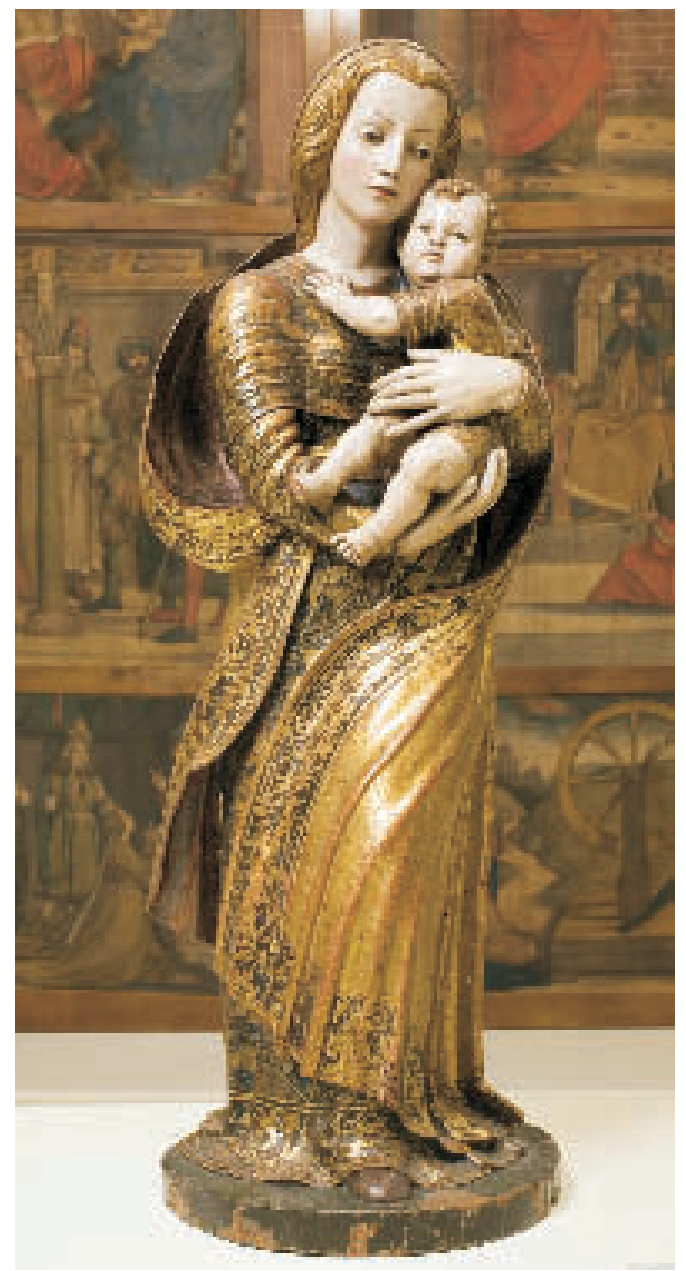

Fig. 3. Colaborador de Diego de Siloé, Virgen con el Niño, 1530-1540 (C).

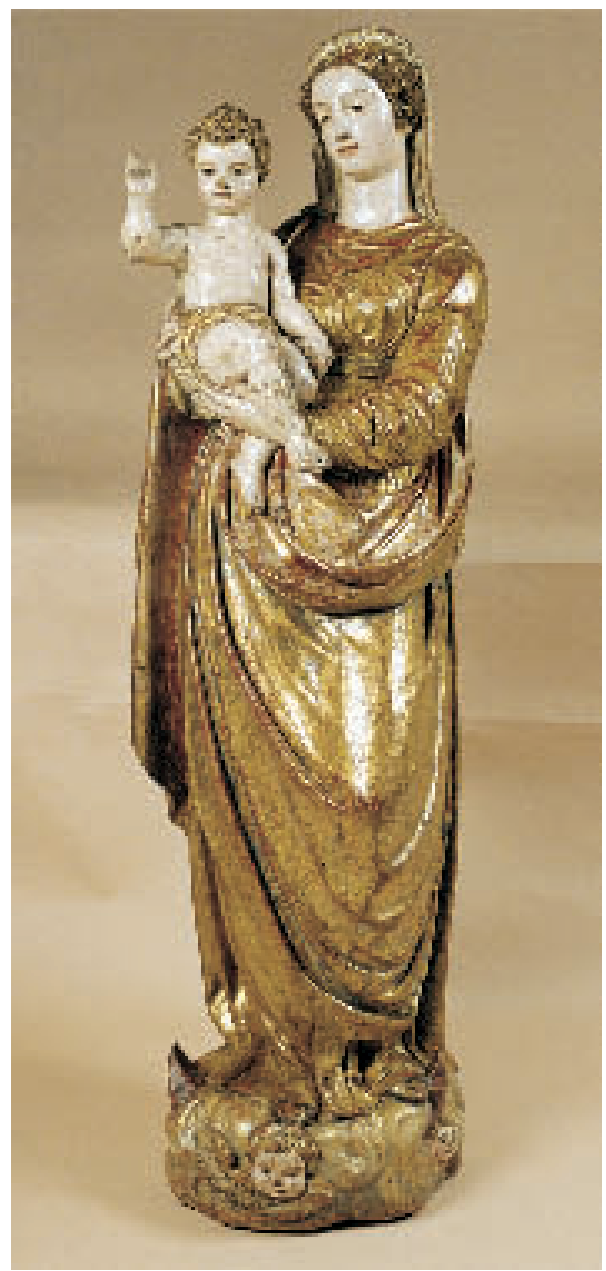

Fig. 4. Jerónimo Hernández, Virgen con el Niño, 1565-1580 (C).

(llamada del Rosario) de la parroquial de Guillena (Sevilla), contratada en 1578, en la que se pueden apreciar los parecidos con el Niño Jesús ${ }^{21}$.

Con los números de inventario 9791 y 9792 encontramos un par de imágenes en alabastro policromado: una Virgen y un apóstol san Juan que miden, respectivamente, $41 \times 15,5 \times 15 \mathrm{~cm}$ y $44 \times 15,5 \times 12 \mathrm{~cm}$. Se trata de las dos figuras de un grupo de La Lamentación al pie de la cruz, obras que se levantan sobre una pequeña peana, y que no están trabajadas por la parte de detrás (fig. 5). La Virgen es una Dolorosa, de pie, mirando hacia arriba, hacia donde estaría la imagen de Jesucristo; le faltan las manos, que debería tenerlas juntas en actitud de implorar. El apóstol san Juan también de pie y con la mirada hacia lo alto, tiene la mano derecha colocada encima del pecho, y con la izquierda sostiene el manto, dejando al descubierto sus pies desnudos. Según el

21 Véase: Palomero PÁramo, Jesús Miguel, Gerónimo Hernández, Sevilla, 1981. 


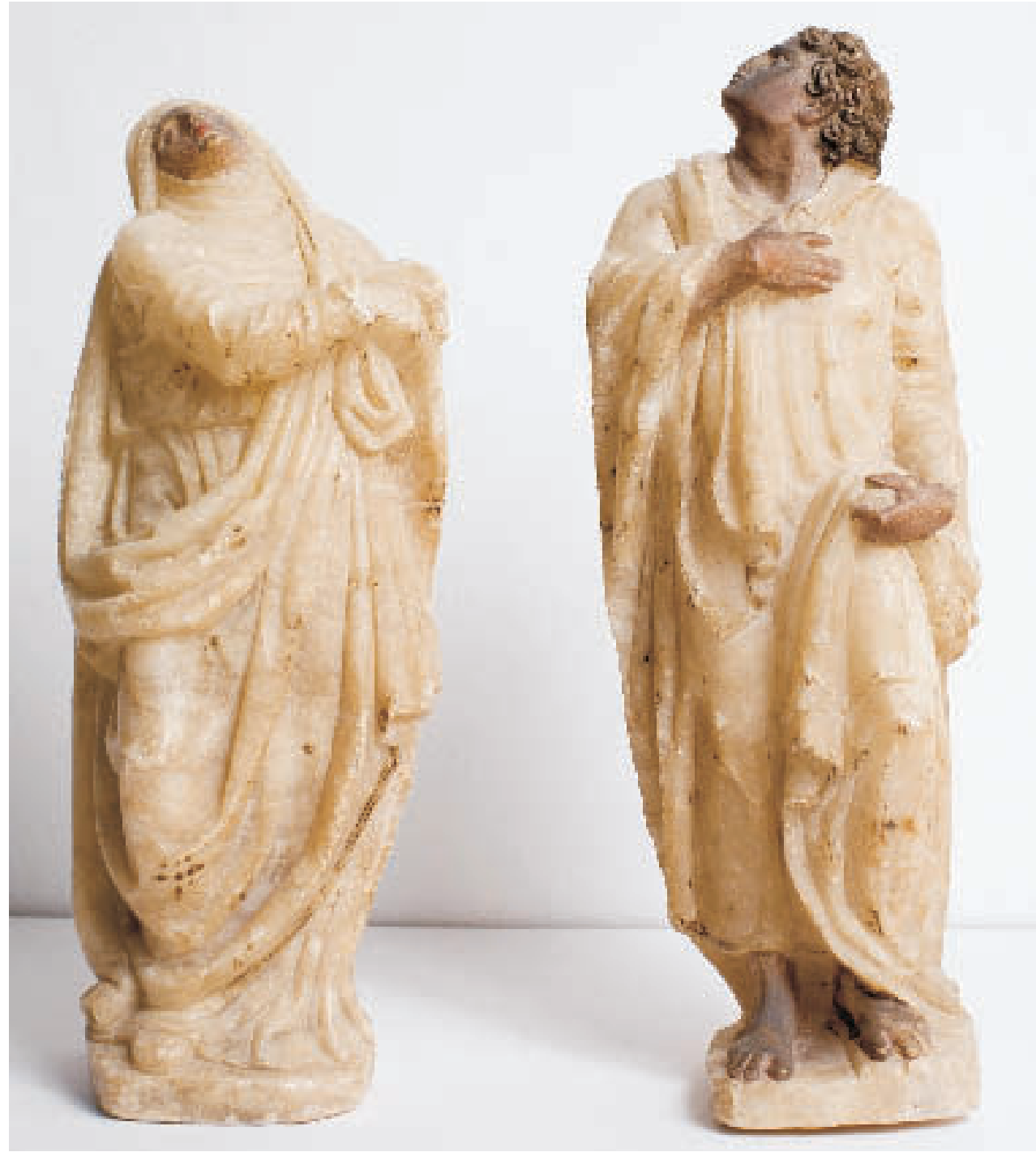

Fig. 5. Taller de Juan de Anchieta, Virgen y san Juan apóstol, 1565-1575 (C).

servicio de documentación del MNAC, las dos obras en cuestión tenían los números 1729 y 1730 en el antiguo Museo Provincial de Antigüedades de Barcelona, y provienen de la población de la Espluga de Francolí (Tarragona). Las dos figuras, con la numeración antigua, no aparecen en el catálogo de Elías de Molins de 1888, pero sí que salen en el catálogo manuscrito del propio Elías de Molins, fechado hacia el año 1900, donde consta que el conjunto fue "adquirido por compra. [Comisión Provincial de Monumentos de Barcelona]". Por lo tanto, se trataría de unas obras ingresadas en el museo entre 1888 y 1900 , en una de las múltiples compras que se hicieron en aquellas fechas. El material alabastrino y la procedencia de la Espluga de Francolí hacen pensar en una obra originaria del monasterio de Poblet, ubicado muy cerca de dicha villa, pero esta cuestión ofrece dudas, sobre todo cuando el anticuario de turno trataría de vender la obra. Las figuras alabastrinas están realizadas por un escultor que abrazó la corriente estilística que en la Península 


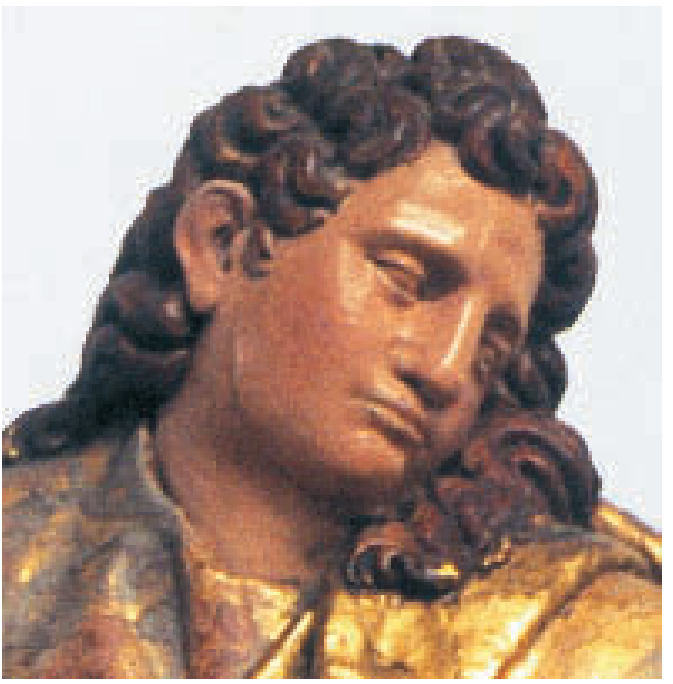

Fig. 6. Juan de Anchieta, cabeza de un santo, detalle del retablo mayor, iglesia. parroquial de Añorbe (Navarra), 1576-1577.

Ibérica se ha etiquetado como "romanismo". Si las piezas fueran originarias del monasterio de Poblet, sólo podrían adjudicarse a Andreu Ramírez (documentado entre 1576 y 1580), escultor habitante de la Espluga de Francolí y activo en el grupo del Santo Sepulcro que hallamos en la galilea del cenobio cisterciense. Sin embargo, a pesar de formar parte de la misma cultura, estas figuras tienen una calidad superior a la mano de Ramírez. En el contexto catalán de finales del siglo XVI sólo podemos pensar en Cristóbal de Salamanca (documentado entre 1576 y 1591), pero tampoco hay ligeras diferencias. En cambio, recuerda muy de cerca el arte de Juan de Anchieta (Azpeitia, 1533-Pamplona, 1588), sobre todo con el estilo que el escultor realiza entre 1565-1575, a caballo entre el retablo de Briviesca (15641569), en colaboración con Pedro López de Gámiz, y las obras aragonesas (1570-1574) ${ }^{22}$. En concreto, se tiene que buscar la autoría entre los miembros de su taller o fieles seguidores: Pedro González de San Pedro (documentado entre 1560 y 1608), o Juan Fernández de Vallejo (documentado entre 1566 y 1599$)^{23}$. Hay que fijarse en la manera de trabajar los pliegues de las ropas y la forma de hacer el cabello. En concreto, puede observarse la semejanza entre el san Juan apóstol del MNAC y el san Bartolomé de Briviesca, con la misma postura de la mano que sujeta un libro, en ángulo recto con respecto al brazo, y también el hecho de que el libro sirva de excusa para arremangarse las vestimentas; o véase cómo utiliza el mismo estilo anguloso y geométrico de los pliegues, que dan una sensación matérica a la ropa, hecho que podemos comprobar tanto en la Virgen del MNAC como en la Asunción de Briviesca; o que el modelo para hacer el rostro del san Juan apóstol del MNAC sea el mismo que un santo que encontramos en el retablo de la parroquial de Añorbe (Navarra), ejecutado entre 1576-1577 (fig. 6).

Con el número de inventario 131124, legado por José Antonio Bertrand Mata en 1970, e ingresado en el museo en 1981, encontramos un busto relicario en madera policromada y dorada que mide $53 \times 38 \times 33,5 \mathrm{~cm}$. Según consta en el catálogo de la colección, anteriormente había sido propiedad de un tal "J. Clavel"; quizás fuera el escultor Jaume Clavell Figueras, entendido en escultura antigua ${ }^{24}$. Se trata de un relicario que representa el busto de santa Inés, que descansa encima de una base octogonal, cortada y dorada, con decoración en la parte frontal: geométrica en las esquinas, de relieves pseudo-vegetales en el centro, y un orificio en el medio para colo-

22 García GaInZA, María Concepción, La escultura romanista en Navarra. Discípulos y seguidores de Juan de Anchieta, Pamplona, 1969; García GainzA, María Concepción, Juan de Anchieta, escultor del Renacimiento, Pamplona, 2008.

23 BARrio LozA, José Ángel, La escultura romanista en La Rioja, Madrid, 1981, pp. 148-171 y 252-253; BARRÓN GARCÍA, Aurelio, "Juan Fernández de Vallejo en Lanciego y Obécuri”, Sancho el Sabio. Revista de cultura e investigación vasca, 1996, pp. 339-356. Véase como González de San Pedro trabaja en Aragón: MoRTE, Carmen, "Dos ejemplos de las relaciones artísticas entre Aragón y Navarra durante el Renacimiento", Príncipe de Viana, 180, 1987, pp. 61-114.

24 Col-leccions Bertrand als Museus de Barcelona, Barcelona, 1985, p. 63. 
car las reliquias (fig. 7). La figura de la santa tiene la cabeza ligeramente girada hacia su izquierda, va peinada con la raya en el medio, con cabello ondulado, y con un velo en la nuca que se sujeta con una diadema, de la cual cuelga una cinta con broche que le llega a la frente. Con su mano izquierda sujeta un corderito, mientras que con el antebrazo derecho sostiene un libro contra el cuerpo y con la mano coge una palma rota. Viste túnica, una sobre-túnica que se ajusta a la cintura con un espectacular cinturón con tiras de cuero (recordando el "balteus", parte del uniforme de los soldados romanos), y un manto que queda recogido con un nudo encima del hombro izquierdo. Por la expresividad de la imagen, la manera de tratar los rizos del cabello, la forma del pelo del cordero, las tiras de cuero que le penden del cinturón, o la decoración en la base del relicario nos lleva a pensar en una obra realizada bajo la influencia de la escultura castellana, en torno a las fechas entre 1560-1580. Una obra de la misma mano se encuentra en la iglesia parroquial de Capillas (Palencia), se tra-

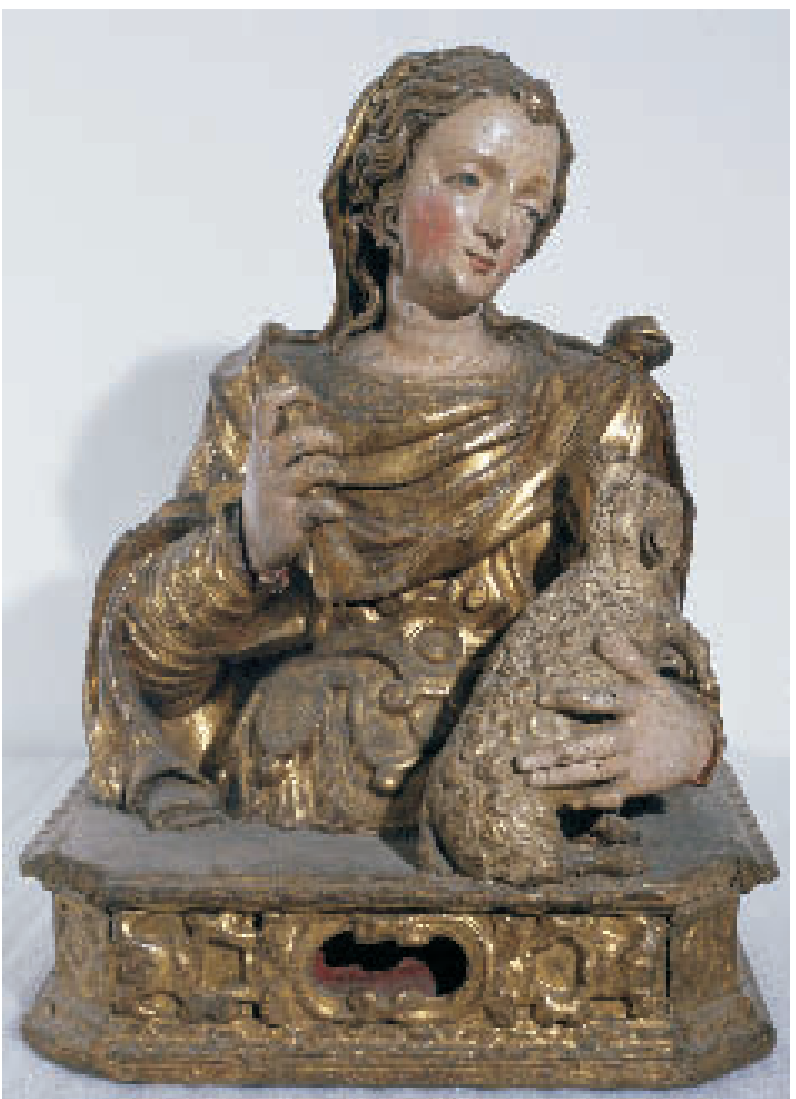

Fig. 7. Maestro de Capillas, busto relicario de santa Inés, 1560-1580 (C). ta de santa María la Blanca (fig. 8); nótese la manera de hacer el cierre de los ojos o los labios pequeños, junto con la forma de las manos, tanto en su grueso como en su disposición. La obra de Capillas fue atribuida a Juan de Juni por Martín González, dada su proximidad estilística y técnica con la producción del maestro francés, y se fecha en una época muy temprana, 1537-1539, a causa del testamento y muerte de Andrés Pérez Capillas, vicario general del obispado de León y comitente de la obra ${ }^{25}$. Es cierto que tanto la obra del MNAC como la de Capillas tienen conexiones con el arte de Juni, ya que, según Portela Sandoval, "la influencia de los modelos de Juni se hace evidente en varias tallas que existen en diferentes iglesias palentinas, testimoniando así la gran difusión de sus modelo"”26. Sin embargo, la manera de hacer los ojos es inédita en Juni, y las obras mencionadas no llegan a las cotas cualitativas del maestro, por lo tanto, se trata de un seguidor. La datación también tendría que ser posterior, y quizás relacionada con una documentación del año 1568, cuando encontramos que los escultores

${ }^{25}$ Martín GonzÁlez, Juan José, Juan de Juni y su época (Catálogo de la exposición. Valladolid, Museo Nacional de Escultura, abril-mayo 1977-Madrid, Dirección General de Patrimonio Artístico y Cultural, mayo-junio 1977), Madrid, 1977, pp. 53 y 101; UrreA, Jesús, “46. Juan de Juni. La Virgen con el Niño”, Memorias y esplendores... (op. cit.), p. 186.

26 Portela Sandoval, F., La escultura del Renacimiento en Palencia... (op. cit.), p. 180. 


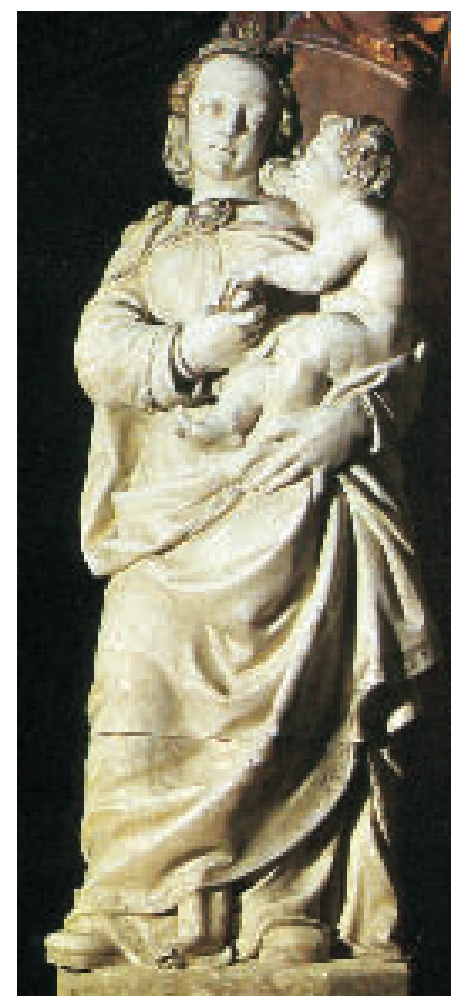

Fig. 8. Maestro de Capillas, santa María la Blanca, Capillas

(Valladolid), hacia 1568.
Juan Mateo de Bolduque e Inocencio Berruguete tenían que hacer un retablo para la misma iglesia de Capillas, pero del cual se desvinculó la familia Bolduque porque el obispo de León, Juan de Santillana, les mandó que fueran a trabajar a Medina de Rioseco. Es necesario tener presente que Inocencio Berruguete, sobrino del gran Alonso, en 1551 trabajaba conjuntamente en Valladolid con Juan de Juni, y que fue un escultor que difundió su arte ${ }^{27}$.

\section{Barroco: Manuel Pereira, discípulo G. Fernández, seguidor de Luis Salvador Carmona}

Con el número 8335, procedente del donativo de Enric Batlló Batlló a la Diputación Provincial de Barcelona, en depósito en el museo desde 1914, hallamos un busto en madera policromada que mide $57 \times 65,5 \times 40 \mathrm{~cm}$. Se trata de la figura de Cristo como Varón de Dolores, habitualmente clasificada como "Ecce Homo", ubicado sobre un pedestal que nada tiene que ver con el busto (base rectangular decorada con molduras y volutas) (fig. 9). La imagen lleva túnica, con los hombros descubiertos, aparece barbada, con cabellos largos, coronado de espinas y con regueros de sangre. Es una obra donde el personaje expresa el dolor, con un tratamiento adecuado del rostro y los músculos en tensión. Según el catálogo de la donación Batlló era una obra anónima del siglo XVII ${ }^{28}$. El hecho de no insistir en lo dramático, su actitud implorante, la mirada dirigida a lo alto, las cejas ligeramente arqueadas, la barba fina, el cabello abundante y trenzado, el rostro y nariz afilados, la boca entreabierta, apuntan claramente hacia Manuel Pereira (Oporto, 1596-Madrid, 1683). Obras de Ecce Homo muy parecidas a ésta se encuentran en el convento carmelita de Larrea (Vizcaya), o en la iglesia parroquial de Longares (Zaragoza) ${ }^{29}$ (fig. 10). Una tipología que también utiliza Alonso Cano en esa misma época, y, con posterioridad, el asturiano Juan Alonso de Villabrille ${ }^{30}$. La datación podría ser entre 1635-1650, pues, a título indicativo, sabemos que la figura de Longares fue confiscada por Diego de Escolano, cuando era inquisidor de Llerena (Se-

27 Portela Sandoval, F., La escultura del Renacimiento en Palencia... (op. cit.), pp. 182-195.

28 Donativo de D. Enrique Batlló y Batlló a la Excma. Diputación Provincial de Barcelona, Barcelona, 1914, núm. 57.

${ }^{29}$ URREA, Jesús, "Introducción a la escultura barroca madrileña. Manuel Pereira", Boletín del Seminario de Estudios de Arte y Arqueología, 43, 1977, p. 262; URREA, Jesús, “Alonso Cano, escultor: su catálogo”, Figuras e imágenes del Barroco. Estudios sobre el barroco español y sobre la obra de Alonso Cano, Madrid, 1999, p. 248. Véase: Canellas López, Ángel, "La capilla de la Anunciación de la parroquial de Longares, fundación del arzobispo Diego de Escolano", Estudios en homenaje al Dr. Eugenio Frutos Cortés, Zaragoza, pp. 81-92.

30 Véase: Urrea, Jesús, "Cano y Pereira contrastados", en E. A. Villanueva-M. Córdoba (coords.), Alonso Cano y su época (Symposium internacional. Granada, 14-17 de febrero de 2002), Granada, 2002, pp. 339-347; Fernández GonzÁlez, M. del Rosario, “26. Ecce Homo. Juan Alonso Villabrille y Ron”, Pedro de Mena y Castilla (Catálogo de la exposición. Valladolid, Museo Nacional de Escultura, diciembre 1989-enero 1990), Valladolid, 1989, pp. $72-73$.

AEA, LXXXIII, 329, ENERO-MARZO 2010, 61-100, ISSN: 0004-0428 


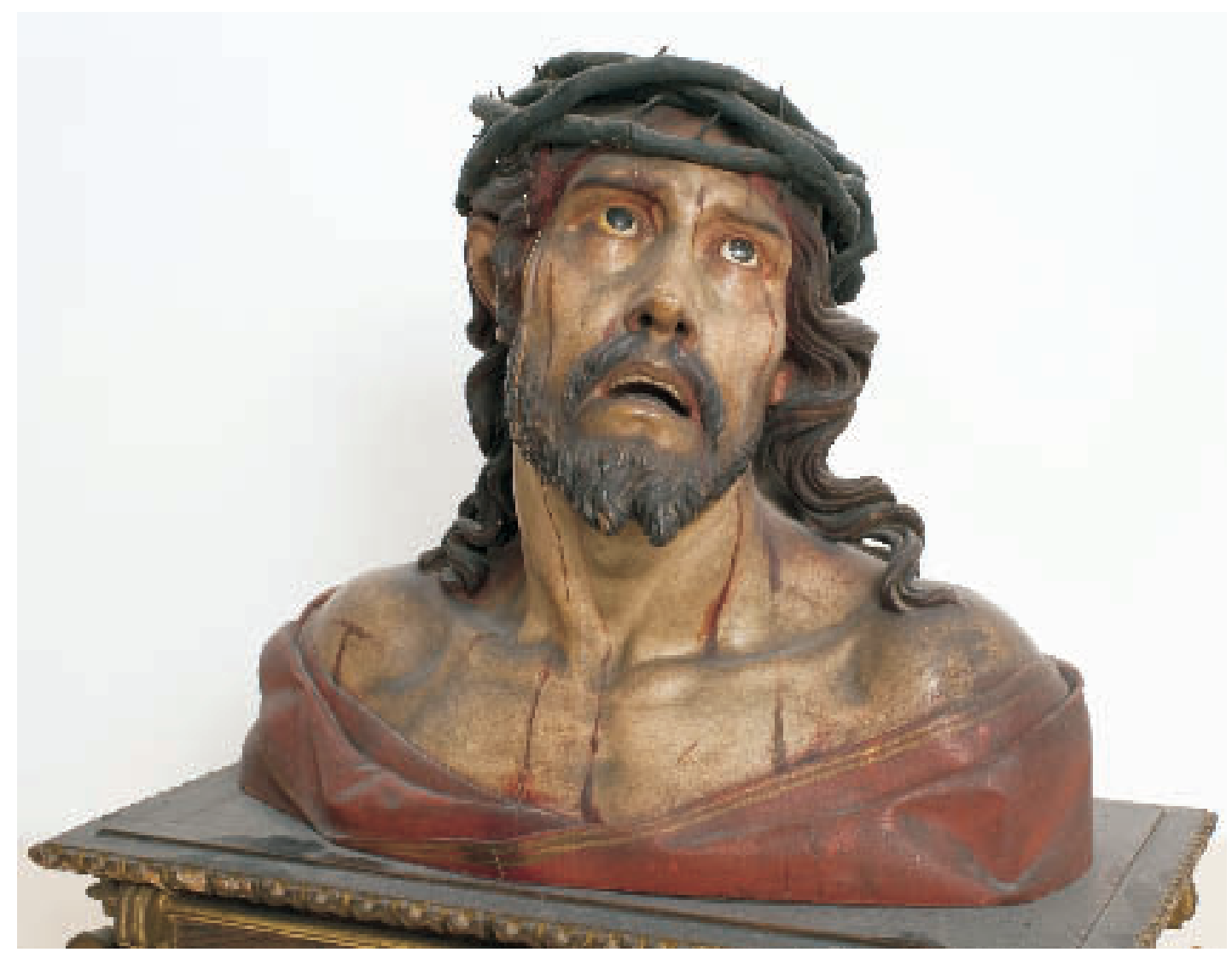

Fig. 9. Manuel Pereira, Ecce Homo, 1635-1650 (C).

villa), entre 1630 y 1638; además, entre 1633 y 1647 Pereira realizó seis de los siete Cristos crucificados que se le documentan.

Con el número de inventario 122068, procedente de un depósito del Ministerio de Educación y Ciencia, encontramos una imagen de la Virgen con el Niño en madera policromada, que mide $120 \times 46,5 \times 38 \mathrm{~cm}$. (fig. 11). María aparece coronada, con la pierna derecha ligeramente flexionada, y con una larga cabellera que le cae sobre los hombros. Viste camisa con orla circular en el escote, túnica decorada con motivos florales, y se cubre con ancho manto que se recoge bajo el antebrazo izquierdo, formando pliegues de acusado relieve. Con el mismo brazo izquierdo sostiene al Niño, y con el derecho aguanta un florón de plata con filigrana. El Niño viste túnica larga de color ocre, lleva el cabello corto,

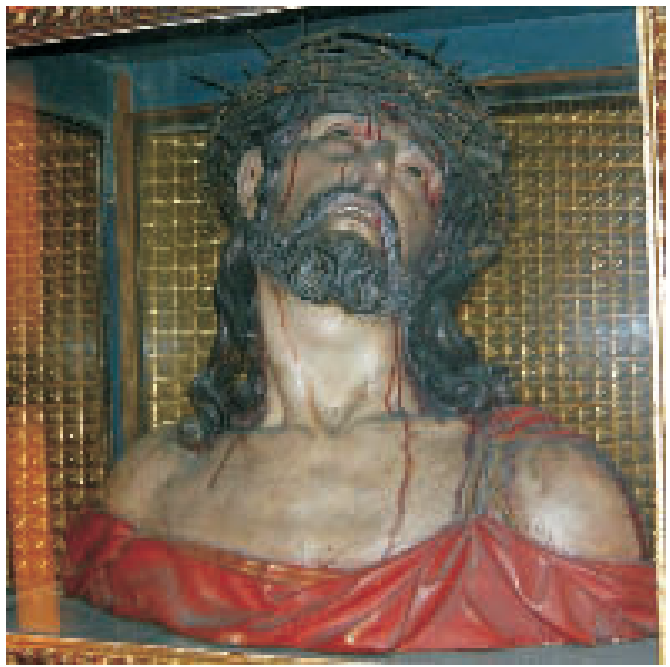

Fig. 10. Manuel Pereira, Ecce Homo, Longares (Zaragoza), 1635-1640. 


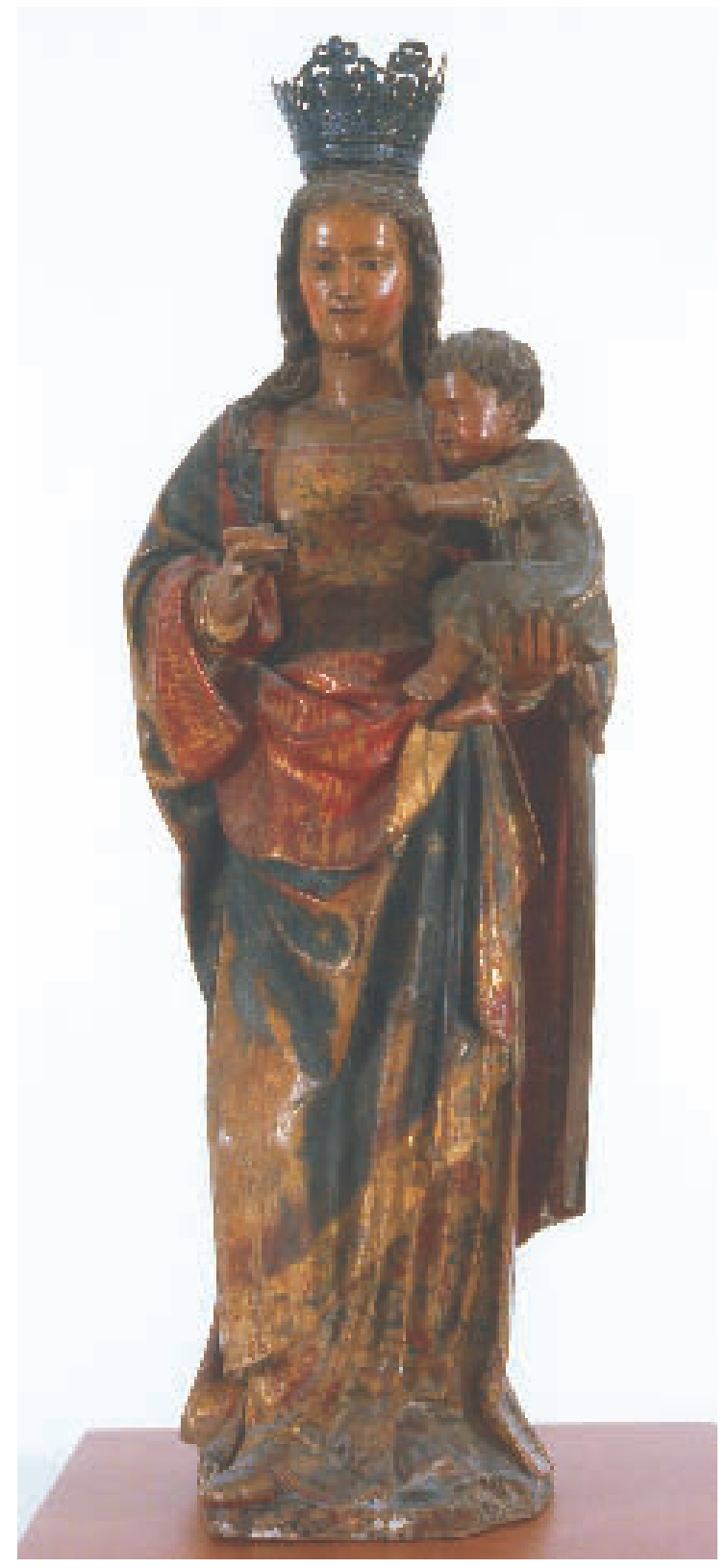

Fig. 11. Discípulo de Gregorio Fernández, Virgen de Canteces, hacia 1643 C. está sentado con las piernas cruzadas, y con los brazos extendidos intenta coger el florón. En la corona de plata de la Virgen leemos una inscripción: SE PARA NUESTRA SEÑORA DE CANTEÇES DIOSE DE LIMOSNA AÑO DE 1643. Según este texto, la figura es la Virgen de Canteces, que originalmente estaría en una ermita de la población de Vega de Valdetronco (Valladolid), cerca de Tordesillas. Dado el contexto geográfico, cronológico y estilístico, la obra se tendría que atribuir a alguno de los discípulos de Gregorio Fernández, pues hallamos algunos caracteres próximos entre la obra del MNAC y algunas de sus esculturas más débiles. Entre éstos, y activos en la fecha de 1643, encontramos a Antonio Salvador (fallece en 1644), Andrés de Ichaso (documentado hasta 1645), Juan Antonio de Estrada (muere en 1647), Antonio de Ribera (documentado hasta 1647), Diego de Gamboa (documentado hasta 1649), Pedro Salvador (expira en 1654), Francisco Alonso de los Ríos (fallece en 1660), o Juan Rodríguez (muere hacia 1675) ${ }^{31}$.

Con el número de inventario 122081 , procedente del antiguo fondo de Museos, encontramos una figura en madera policromada que mide $83,5 \times 35,5 \times 30$ $\mathrm{cm}$. Se trata de la imagen de Jesucristo arrodillándose encima de un globo terráqueo, donde hay pintada la escena del pecado original de Adán y Eva. Cristo es el redentor del pecado, su sacrificio se expresa mediante su muerte. Jesucristo, vestido con un simple paño de la pureza, lleva la soga al cuello y aparece coronado de espinas, momentos antes de la crucifixión, con los brazos abiertos en actitud suplicante hacia Dios Padre. El manto cubre una parte del globo. El

31 Véase: UrReA, Jesús, "El escultor Francisco Alonso de los Ríos (¿-1660)”, Boletín del Seminario de Estudios de Arte y Arqueología, 38, 1972, pp. 355-369; UrreA, Jesús, "Escultores coetáneos y discípulos de G. Fernández, en Valladolid”, Boletín del Seminario de Estudios de Arte y Arqueología, 50, 1984, pp. 349-370; UrREA, Jesús, “Escultores coetáneos y discípulos de Gregorio Fernández, en Valladolid' II", Boletín del Seminario de Estudios de Arte y Arqueología, 58, 1992, pp. 394-402. 
conjunto se levanta sobre una peana moldurada (fig. 12). Esta obra toma el modelo de una obra conocida: el Cristo del Perdón, realizada en 1648 por Manuel Pereira, para la iglesia conventual de Rosario, destruida en un incendio en $1936^{32}$. En la segunda mitad del siglo XVII encontramos diferentes autores que se inspiran en este tipo iconográfico, y realizan una serie de obras relativamente similares: en 1656 Bernardo del Rincón hace el Cristo del Perdón, actualmente conservado en la iglesia de San Quirze y Santa Julita de Valladolid, o el 1670 Pedro Roldán fabrica el Cristo de la Caridad, custodiado en la capilla de San Jorge de Sevilla ${ }^{33}$. A mediados del siglo XVIII hay un avivamiento de este modelo iconográfico, gracias al escultor académico Luis Salvador Carmona (Nava del Rey, 1708-Madrid, 1767), que realizó tres versiones: en febrero de 1751 había acabado la que se conserva en la iglesia de Nuestra Señora del Rosario en el Real Sitio de la Granja de San Ildefonso (Segovia), tuvo mucha fama y su hermano, Juan Antonio Salvador Carmona, hizo un grabado; en 1753 concluyó el del Hospital de Santa Ana de Atienza (Guadalajara); y en 1756 el del convento de capuchinas de su villa natal, Nava del Rey (Valladolid) $^{34}$.

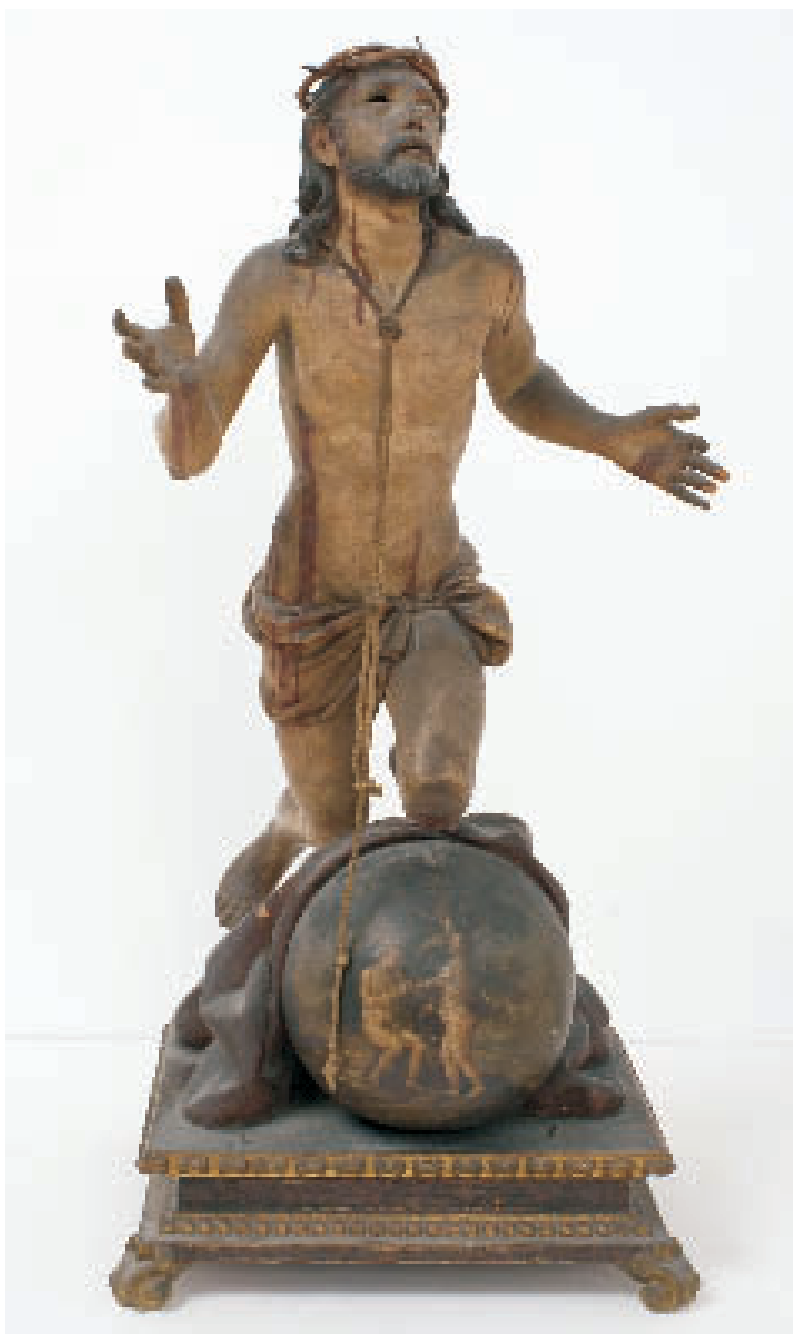

Fig. 12. Seguidor de Luis Salvador Carmona, Cristo del perdón, 1755-1775 C).

JOAN YEgUAS I GASSÓ Conservador del Museu Nacional d'Art de Catalunya

32 Hernández Perera, Jesús, "El Cristo del Perdón de Manuel Pereira", Homenaje al profesor Martín González, Valladolid, 1995, pp. 365-372.

33 Véase: Fernández del Hoyo, María Antonia, "El Cristo del Perdón, obra de Bernardo del Rincón", Boletín del Seminario de Estudios de Arte y Arqueología, 49, 1983, pp. 476-480; BernAlEs, Jorge, Pedro Roldán, maestro de escultura 1624-1699, Sevilla, 1973.

34 Véase: Martín GonZÁlez, Juan José, Luis Salvador Carmona. Escultor y académico, Madrid, 1990, pp. 78-79, 226-227, 277-281. 